\title{
MEANING OF SELF-CARE: LIVED EXPERIENCES OF IRANIAN DIABETIC PATIENTS
}

\author{
Azizzadeh Forouzi $\mathbf{M}^{\mathbf{1}}$, Tirgari Batool ${ }^{2}$
}

\begin{abstract}
BACKGROUND: Diabetes continuously disrupts a patient's well-being and quality of life. Successful self-care could potentially decrease overall costs and rates of mortality and morbidity. Patients' experiences could be used to elucidate what they believe about illness and its management. The overall aim of this study was to illuminate the meaning of self-care among diabetic patients in Southeast of Iran. METHODS: Sixteen diabetic patients with a mean age of 34 and 10 years' experience in self-care for their disease were interviewed. The interviews were recorded, transcribed verbatim, and analyzed with a Ricoeur's phenomenological hermeneutic method.

RESULTS: The meaning of self-care was comprehensively understood as being empowered. This can be divided into four themes: seeking information, being independent, being optimistic or pessimistic and trust in God.

CONCLUSION: The results in this study suggest that cultural and religious components could affect diabetic patients' self-care. Nurses might use patients' religious beliefs to relieve their stress, help them to retain a sense of control, maintain hope and sense of meaning and purpose in their life.

KEYWORDS: self-care, Diabetic patients, IRAN
\end{abstract}

DOI: http://dx.doi.org/10.4314/ejhs.v25i2.10

\section{INTRODUCTION}

Diabetes mellitus is one of the serious health challenges in the world and is linked to high mortality and morbidity (1) that puts a much bigger responsibility on the patient to make healthcare decisions (2). The World Health Organization (WHO) estimates that diabetes is becoming a global epidemic of the $21^{\text {st }}$ Century, and that over $70 \%$ of known cases of diabetes belong to developing countries (3). In Iran, the prevalence of disease is reported to be between $2 \%-10 \%$ among adults (4). One of the biggest challenges for patients is how to obtain the necessary skills to effectively manage their diabetes (5). Therefore, self-care responsibility remains lifelong and complex, creating many personal challenges for patients (2). The focal tasks of diabetes self-care include medication adherence, self-monitoring blood glucose, nutrition adjustment, exercise, foot care, coping with the illness, and monitoring the disease symptoms and its progression (6). According to
American Diabetes Association (2003)self-care abilities include the capability to use diabetes knowledge to balance physical, emotional, and activity levels and manage medications and nutritional intake to achieve optimal glycemic control (7).There are several definitions for selfcare in diabetes. Self-care is an evolutionary process of development of knowledge or awareness by learning to survive with the complex nature of the diabetes in a social context (8) or the individual's self-identified management abilities. Orem (1991) defines self-care as "learned behavior composed of deliberate goals that direct actions" that are perquisites by "knowing" and "deciding (9). Through successful self-care, patients could decrease overall costs and their own rates of mortality and the morbidity (10). In contrast, neglecting self-care can have negative effects on body, mind and spirit and leave patients out of balance (11).

\footnotetext{
${ }^{1}$ Neuroscience Research Center, Institute of Neuropharmacology, Kerman University of Medical Sciences, Kerman, Iran

${ }^{2}$ Physiology Research Center, Kerman University of Medical Sciences, Kerman, Iran

Corresponding Author: Batool Tirgari, Email: b_tirgari@kmu.ac.ir
} 
Reviewing the literature showed that there are some studies that explored self-care in diabetes in different contexts. Collins et al (2009)conducted a study on diabetics patients in Ireland based on indepth interviews. They revealed that patients' perceptions effect on their self-care competence in dietary planning, testing blood sugar, and getting regular exercise (5). Thorne et al (2003) reported that patients with diabetes perceived self-care decision making as a complex process that occurred within the context of a disease trajectory, a healthcare culture, and a uniquely meaningful life that involved assuming control, fine tuning the basis on which decisions were made, and constantly evaluation their self-care decisions (12). In another study, Hjelm and Bard (2013) compared the self-care behaviors and beliefs of diabetic Swedish women with diabetic migrant Yugoslavian women living in Sweden. They found a clear difference between the two groups. The Yugoslavian diabetics had a more passive attitude toward their illness and their self-care, relying on cultural traditions. They showed less inclination toward self-care. In contrast, the Swedish diabetics expressed themselves in terms of medicine and healthy lifestyles and took an active role in self-care (13). Therefore, diabetic patients are not homogenous. Their gender, racial background, individual attitudes, personalities and cultural beliefs play an important role in diabetes self-care management (14). Studies conducted in Iran have been mostly quantitative studies. In the Iranian context, no study was found to explore the meaning of self-care among diabetic patients. The meaning of self-care may also possibly be associated with the context of a disease trajectory, healthcare culture, individual attitudes, personalities and cultural beliefs. Therefore, the aim of this study was to explore the lived experiences of self-care among diabetic patients in Southeast Iran. Participants were asked to narrate their experience of self-care. As necessary, clarifying and encouraging questions were used such as: Can you explain a little more what you mean? Can you give me an example? During the interviews, the researchers attempted to strike a balance between talk about the story by participants and keeping to the aim.

\section{METHODS}

Design: This qualitative phenomenological study employed in-depth, face-to-face, and semistructured interviews to study the lived experiences of phenomena that are somehow related to human interactions. For this purpose, phenomenology is an appropriate method, which deeply explores the experiences and meanings of complex phenomena (15). This method focuses on the meaning of human experiences while studying their subjective consciousness (16). Phenomenological-hermeneutic method is developed for interpreting interview texts, trying to obtain a deeper understanding of the experience of the phenomenon (17) in focus, which in this study was the meaning of self-care among diabetic patients.

According to Charalambous (2014) Hermeneutic phenomenology is consistent with the nursing paradigm that views the person as one who is constantly interacting with the environment, interpreting impressions and ascribing personal meaning to the experience (18).

Morse and Field (1995) stated that the inductive method of phenomenological research provided a way to explore the diabetic experience in its context (19), and the hermeneutic phenomenological method facilitated the construction of a full description of some aspects of the diabetics' life world (20). Phenomenology enhances the understanding of the lived experiences of the individual and their intentions within their daily life experiences (21). Thus, using a hermeneutic approach inspired by Ricoeur, self-care phenomena were studied from the viewpoint of the diabetic patients with the focus on how they interpreted their experience of selfcare.

Participants: All patients with diabetes referred to the diabetic center supervised by Kerman University of Medical Sciences in Southeast Iran were considered as potential participants. A total of 16 ( 7 men and 9 women) diabetic patients participated in this study. It was saturation that limited the number of participants to 16 . The interviewees' ages were between 30 and 76; they had 10 years' experience in self-care for their disease. The inclusion criteria were the following: an elapse of at least one year since diabetes 
diagnosis, no co-morbidity, psychiatric disorders, and ability to communicate.

Data collection: The main approach to collecting data was based on a qualitative method. These consist of narrative interviews. In-depth individual, semi-structured audio-taped interviews were conducted with the participants. The interviews were taped recorded, transcribe verbatim and analyze consecutively by the authors. All interviews took one session, according to participants' requests. Each session was between 45-55 minutes. Purposeful sampling was used primarily and continued with theoretical sampling based on emerged themes. The interview guide was initially developed with the help of the second author (B.T.). As the study progressed, theoretical sampling was used to guide further data collection. This involved collecting more data to examine initial themes and their relationships and to make sure representativeness in the categories that exist by seeking additional informants for interview together with contextual data. Seeking for additional informants stopped when data saturation occurred.

Ethical consideration: Ethical issues in this study involved assurance of confidentiality and autonomy for the participants. Permission, as written informed consent, was obtained from the participants for the audiotape interviews. Besides, a formal letter of introduction was obtained from the Vice Dean for Research of Kerman Medical Sciences.

Data analysis: The principles of phenomenological hermeneutics influenced by Ricoeur and described by Lindseth and Norberg (17) was used for data analysis.

Hermeneutic phenomenology as a philosophical movement originates with Martin Heidegger (1889-1976) and was developed by Heidegger's student, Hans-Georg Gadamer (1900-2002) among others. Phenomenology was inaugurated earlier by Edmund Husserl (18591938) (22).

The method of interpretation proceeded through three phases. The first phase was a naïve reading. The naïve reading entailed that the researcher read the text as a whole to become familiar with it and begin to formulate thoughts about its meaning for further analysis. The naïve interpretation was a preliminary interpretation of the whole and led to a first, spontaneous interpretation and an examination of the influence of the researcher's pre-understandings. The interpretive process was progressed by identifying patterns of meaningful connection through the second interpretive step and it is known as the "structural analysis". This step aimed to discard or validate the first guesses deriving from the naïve reading.

The second step was a structural analysis. The text was divided into meaning units, which were condensed and abstracted to form subthemes and themes. The themes were reflected upon and compared to the naïve understanding. The process of condensation and validation was repeated until the naïve understanding was validated by the structural analysis.

In the third step, the whole text was reread with an open approach. In this phase, the naïve understanding and structural analysis were woven together to reach a comprehensive understanding of the whole in relation to the authors' preunderstanding, the research question and the relevant literature.

In the first phase, the interviews were read by all authors with an open mind to gain a naïve understanding of the meaning of self-care for diabetic patients and to initiate creation of an approach for further structural analysis. Next, a structural analysis was done, in which parts and structure of the text were decontextualized and systematically analyzed to invalidate or validate the naive understanding. Finally, a comprehensive understanding was formulated. This was based on a dialectical movement between understanding and explanation, between the whole and the parts of the text, and was the final of several possible interpretations of the text that the authors unanimously agreed upon. All the authors as a team were involved in all steps of analysis.

Credibility: The credibility of the findings was established by prolonged contact over duration of 2 months with the participants and having other researchers analyzed pieces of data independently. The coded data were then categorized and interpretations were compared. The objectivity of the data was enhanced by ensuring theoretical sensitivity whereby the researchers put aside any preconceived ideas about the topic during its analysis. The participants were also contacted after the analysis was completed to verify the interpretations of the researchers. The results were 
also checked with some of the diabetic patients who did not participate in the research, and they confirmed the fitness or applicability of the results as well.

Through the connection between naïve understanding, structural analysis, and the interpreted whole, the rigor of the study was confirmed. Through this hermeneutic act, we tried to understand the text by following its movement from what it says to what it talks about. Through the mediating role of the structural analysis, both the justification of the objective approach and the rectification of the subjective approach to the text were constituted. However, the trustworthiness of the analyses is to some degree open to the reader.

\section{RESULTS}

Naive understanding: According to the interview text, diabetic patients struggled to create the meaning of self-care as a balance between the dependency and independency. Independency demanded patients to seek information about dietary modification, drug and exercise regimens. Developing knowledge and awareness resulted in appropriate decision making to become empowered self-managers. They tried to be independent in managing medications and nutritional intake to achieve optimal glycemic control. Optimistic thinking played a key role in patients to become independent. Optimistic thinking caused participants to be able to manage various psychological and physical aspects of diabetes and therefore achieve expected positive future outcomes. They believed that making suitable decisions regarding their situation would improve their well-being. Being optimistic enhanced participants' ability to use appropriate coping strategies and effectively adapt to their disease.

Structural analysis: In the structural analysis, the text was divided into meaning units that were further condensed, compared across the interviews, grouped, and labeled (Table 1).
Finally, the labeled groups of the meaning units were abstracted into one main theme and four subthemes (Table 2).

The meaning of self-care was comprehensively understood as being empowered. This can be divided into four themes: seeking information, being independent, a tension between optimistic and pessimistic views and trust in God.

Seeking information: The text revealed that selfcare means to be actively aware of diabetes, diet, exercise, take medication, and test glucose level. Participants stated that effective self-care requires valid information from different sources. They mentioned that doctors, nurses, similar patients, TV educational programs on this topic were most powerful sources of information to enhance their ability of self-care and to learn how to use it in daily living. Some participants received proper information from health care providers and educational programs. They believed that this information empowered them to carry out the DM regimen required and resulted in better quality of life. They said that absence of valid information led to use of wrong strategies for self-care.

learn and understand diabetes, you can use the radio and TV programs. I must go to the Diabetes Center. Diabetes Center classes are good and helpful. In this condition, the patient information is much better because he can take care of himself.

He continued:

I'm trying to know everything about diabetes. Last night I read in the newspaper that pancreas transplantation may be done to treat diabetic patients. I read a lot about diabetes diet and exercise. I learned a lot from doctors and nurses. Diabetes is associated with me and if I understand what I do every day, my survival may be longer and I have a better life.

Being independent: The text revealed that selfcare means being independent. Participants mentioned that being dependent on others provokes sense of weakness and not being able to meet his/her own needs. 
Table 1: The hermeneutic phenomenological structural analysis

\begin{tabular}{|c|c|c|c|}
\hline Meaning unit & Condensation & Subtheme & Theme \\
\hline $\begin{array}{l}\text { I think doing work properly, } \\
\text { depending on the information I have } \\
\text { about diabetes. }\end{array}$ & $\begin{array}{l}\text { Information is } \\
\text { necessary for self-care }\end{array}$ & $\begin{array}{l}\text { Being aware through } \\
\text { acquired information }\end{array}$ & $\begin{array}{l}\text { Seeking } \\
\text { information }\end{array}$ \\
\hline $\begin{array}{l}\text { To learn and understand diabetes, } \\
\text { you should listen to doctor, Radio and } \\
\text { TV programs. Also Diabetes Center } \\
\text { classes are good and helpful }\end{array}$ & $\begin{array}{l}\text { Need to learn from } \\
\text { health providers, } \\
\text { media and diabetes } \\
\text { Center }\end{array}$ & Meeting learning needs & \\
\hline $\begin{array}{l}\text { I want to do everything myself. } \\
\text { No one else could do my work even } \\
\text { my children. }\end{array}$ & $\begin{array}{l}\text { Doing everything by } \\
\text { my self }\end{array}$ & $\begin{array}{l}\text { Not depending on } \\
\text { another's }\end{array}$ & Being independent, \\
\hline $\begin{array}{l}\text { God give me the strength to take care } \\
\text { of myself. I wish I could do all my } \\
\text { own work. }\end{array}$ & Ability to self care & $\begin{array}{l}\text { Being strength to self } \\
\text { care }\end{array}$ & \\
\hline $\begin{array}{l}\text { I feel that self-care means doing } \\
\text { things by me and did not need } \\
\text { another. }\end{array}$ & $\begin{array}{l}\text { Doing things by self } \\
\text { means self care }\end{array}$ & $\begin{array}{l}\text { Independency as self } \\
\text { care }\end{array}$ & \\
\hline $\begin{array}{l}\text { It is a dreadful disease. I am deprived } \\
\text { of many foods and will lose my } \\
\text { organs. Heart, eye and Renal function } \\
\text { is impaired. }\end{array}$ & $\begin{array}{l}\text { Deprivation form } \\
\text { normal life style }\end{array}$ & $\begin{array}{l}\text { Being pessimistic } \\
\text { Being hopelessness }\end{array}$ & $\begin{array}{l}\text { A tension between } \\
\text { optimistic and } \\
\text { pessimistic }\end{array}$ \\
\hline $\begin{array}{l}\text { My mother and father have diabetes. } \\
\text { Their organs are now impaired. I see } \\
\text { what problems they have. My father's } \\
\text { eyes do not see. My mother's leg is } \\
\text { ulcerous and experienced myocardial } \\
\text { infarction. }\end{array}$ & $\begin{array}{l}\text { Negative view about } \\
\text { future of disease }\end{array}$ & Being optimistic & \\
\hline $\begin{array}{l}\text { Diabetes is a common disease that } \\
\text { everybody can have. Diabetes is } \\
\text { manageable .I have positive feeling to } \\
\text { myself because my disease can be } \\
\text { controlled. }\end{array}$ & $\begin{array}{l}\text { Having positive } \\
\text { feeling }\end{array}$ & & \\
\hline $\begin{array}{l}\text { Everything is in God's hands. My } \\
\text { disease is God willing. }\end{array}$ & Disease is God willing & $\begin{array}{l}\text { Believing to God } \\
\text { willing }\end{array}$ & Trust to God \\
\hline $\begin{array}{l}\text { When I feel that I can't do anything, I } \\
\text { remember my God. I asked God for } \\
\text { help. }\end{array}$ & Asking help from God & Believing to God power & \\
\hline God is forgiving and merciful. & God forgiveness & $\begin{array}{l}\text { Believing God } \\
\text { companionate }\end{array}$ & \\
\hline
\end{tabular}


Table 2: The Comprehensive Understanding and Subthemes Found in the Structural Analysis of the meaning of self-care

Comprehensive Understanding

Being empowered

\section{Themes}

\author{
Seeking information
}

Being independent

A tension between optimistic and pessimistic

Trust to God
Seeking information is an effort to assume control on diabetes. Learning was evident in the 32 years old man statements regarding the importance of gathering information through multiple sources. He described how seeking information promote diabetes self-care:

I think doing work properly depending on the information I have about diabetes. We should listen to the doctors and learn what they say. To

In the Iranian context, kinship relationship seems to be a big source of support for patients with chronic diseases, but participants in this study experienced it as a negative aspect of family support. They stated this type of support decreases their sense of independence. It caused patients' feeling of weakness, dependence and lack of selfcontrol.

A 47 years old man reflected on his children's support, and described being dependent on family decreased his ability to take care of him: I want to do everything myself. No one else could do my work even my children. God give me the strength to take care of myself. I do not want to be dependent to my family. I wish I could do all my own work. I feel that self-care means doing things by me and did not need another.

$\mathrm{He}$ continued by discussing the impact of information and learning on his independence: Commonly, anyone who knows is capable. When you know about diabetes, you do not need anyone.... I must do everything myself. I'm trying to learn how to do my training... Wanting is able.

Tension between optimism and pessimism: Patients' opinions about self-care were formulated based on similar situations previously experienced by members of their own families. If these experiences were negative, they expect negative outcomes for their diabetes in the future. A sense of helplessness takes over and they believed that they are unable to change disease conditions. They had negative explanatory style or were pessimistic. Patients who were exposed to parents' bad experiences about diabetes were more likely to go on to develop a pessimistic attitude toward self-care. Conversely, patients who had similar situations experienced by their own family members had a positive explanatory style or were optimistic. These patients had high spirit and were positive about their abilities for self-care. Highly optimist patients were significantly more satisfied with their self-care with the reverse being true for the low optimists. Optimistic patients experienced positive coping strategies such as problem-focused coping. They were empowered in diabetes selfcare and experienced more control over disease conditions.

A 35 years old women stated that her parents were diabetic and she shared her parents' story during the interview, illustrating the negative outcomes for her diabetes in the future.

It is a dreadful disease. I am deprived of many foods and will lose my organs. Heart, eye and Renal function is impaired. My mother and father have diabetes. Their organs are now impaired. I see what problems they have. My father's eyes do not see. My mother's leg is ulcerous and experienced myocardial infarction.

One optimist patient (5 years since diagnosis) was actively engaged in self-care behaviors, and in her view, diabetes is a common disease. While realistic and accepting of the diabetes diagnosis, she was hoping for a return to "normal" and her pre-diabetes state. During the interview, she acknowledged the possibility that she may need to continue with medication for the treatment of her diabetes and discussed her plans to optimize selfcare 
Diabetes is a common disease that everybody can have. Diabetes is manageable ... It's not bad. If you manage it, it can be controlled ....I have positive feeling to myself because my disease can be controlled.

Trust in God: Participants revealed philosophical explanations of their disease, mainly saying that it was God's will and they had to accept this illness because they could not do anything about it. Participants relied on God to cope with their illness. Patients who participated in this study alluded to God to reduce their emotional distress. They referred to their Islamic beliefs as a way to achieve empowerment. Their faith in God was highlighted as the main element in their lives and assisted them to cope with challenges that emerged by DM.

A 40 years old participant reflected on her Islamic beliefs in the following statements:

Every morning I would speak with God. God hears speaking of patients. Everything is in God's hands. I do not have any role in my disease. Whenever I feel that I do not work, remember God. I asked God for help. After I had a relationship with God, I feel good.

Another participant focused on God's willing and forgiveness and stated:

God is forgiving and merciful. I asked God for help. My disease is God willing. I hope to God, for healing. Whatever God gives me is good.

Comprehensive understanding: The patients' self-care was described as "being empowered". This is in line with Persian poet Hakim Abolghasem Ferdowsi's (940 - 1020 CE) poem about the empowering where he says: "Capable is he who is wise" (in Persian: توانا بود هر كه دانا بود:) This hemistich is translated into English as "knowledge is power" or "One who has wisdom is powerful".

Knowledge plays an important role in all spheres of a patient's life. It is a powerful factor which helps diabetic patients to attain success and power. The power of knowledge as well as the connection to higher being and having optimistic thinking is great. Theses give diabetic patients the ability to make better decisions, come up with more evolved and intelligent thoughts and improve their lives. It helps patients to overcome their weakness and faults and face difficulties with courage and confidence. These give them mental, moral and spiritual advancement. Besides, it is through knowledge, spirituality, independence and optimistic thinking that diabetic patients have gained mastery over nature, and so do not necessarily need anyone or anything to be successful. Independence is power because it allows them to have the power to speak their mind, the power to be who they truly are and the power to do whatever makes them happy. They will absorb so many things that have the potential to dramatically improve their life. That is why knowledge is so important.

\section{DISCUSSION}

The study revealed that the diabetic patients' selfcare was described as being empowered. By the tradition, the success of patients to control or manage their diabetes has been judged by their empowerment to prescribed therapeutic regimen (23). According to Steed et al (2003), patients' ability to be involved in the diabetes care seems to be grounded in psychological and motivational factors such as being active in empowering themselves (24). Funnell and Anderson (2004) explained that empowerment is a patient-centered, collaborative approach tailored to match the fundamental realities of diabetes care. It is also, defined as helping patients discover and develop the inherent capacity to be responsible for one's own life. They go on saying that empowerment is not a technique or strategy, but rather a vision that guides each encounter with our patients and requires that both professionals and patients adopt new roles (23). Tol (2013) argued that ability and innate capacity of diabetic patients empower them to cope better with their disease, and it can be achieved by empowerment of patients that is a vital concept of promoting their overall well-being (4).

The study revealed that Iranian diabetic patients experienced self-care as seeking information. According to de Silva (2011) successful self-care requires knowledge about the condition and what needs to be done. This might also include recognizing changes and learning how to cope with challenges emerged by diseases. It is essential that information about the condition, education and training are key components of the self-management approach. It also needs to be recognized that people who have more than one long-term condition will need the information, skills and training to manage the different needs of 
their conditions (25). Funnell and Anderson (2004) demonstrated the patients' need to learn about diabetes and how to safely care from it on a daily basis. They also need information about various treatment options, the benefits and costs of each of these strategies, how to make changes in their behaviors, and how to solve problems. They concluded that, patients need to understand their role as a decision maker and how to assume responsibility for their care (23).

Diabetic patients experienced self-care as being independent. They mentioned that being dependent on others provokes a sense of weakness and not being able to meet his/her own needs.

In the Iranian context, kinship relationship seems to be a big source of support for patients with chronic diseases, but participants of this study experienced it as a negative aspect of family support. In addition to family member attempts to support patients, qualitative studies suggest that family members can also pose barriers to self-care $(26,27)$ and were associated with lower selfefficacy and self-management adherence. Rosland et al (2013) stated that Patients with chronic illness do not always experience family support positively (28).Wang et al (2012) also found that patients' self-care behavior was negatively correlated with family caregivers' caring behavior. They elaborate that family caregivers' caring behavior had a partial negative effect on patients' self-care behavior. According to them, the relationship between patients' self-care behavior and their caregivers' involvement was complex (29).The main point relating to the management of chronic diseases such as diabetes is to encourage patients to take greater responsibility for their care, and to be independent in self-management practices (4).

The meaning of self- care, as revealed in the text, was a tension between optimism and pessimism. Patients' opinions about self-care were formed based on their past experiences about diabetes encountered by their family's members. Fournier et al (2002) determined the role of optimistic beliefs in adaptation processes of three chronic diseases (type 1 diabetes mellitus, rheumatoid arthritis and multiple sclerosis) in controllability by self-care. They found that when chronic disease must be controlled by self-care, physical health depends more strongly on positive efficacy expectancies. In contrast, when self-care options for controlling chronic disease are limited, physical health depends more strongly on positive unrealistic thinking and relates negatively to positive efficacy expectancies (30). Optimistic thinking has been found to be clinically important in terms of the way people deal with hopelessness and depressive thinking. Optimism is the belief that future life events will have positive outcomes. Attritional styles are formed by the way we perceive or explain past life experiences. Explanatory style is the way people determine the outlook of his/her life based on past experiences. In comparison, those who blame themselves for misfortunes (internal factors) and believe they will never amount to anything are said to have negative explanatory style or are pessimistic (31).

Diabetic patients experienced self-care as trust in God. Participants believed that cause or cure should be seen as God's will. They stated that it is God's will, and they have to accept this illness, and as a result, relied on God to cope with their illness.

In earlier studies about spiritual care in Iran, Tirgari et al (2013) and Iranmanesh et al (2012) argued religious beliefs were the main values that gave meaning to patients' lives and assisted them in dealing with disease. They go on that religious patients considered their disease as a means to become closer to God who helps patients to heal $(32,33)$.

Islam is the dominant religion in Iran. The majority of patients in Iran chose to express their spirituality through religious practices. Spirituality is perceived to be synonymous with religious beliefs and practices (32). Due to the Islamic belief that all events, including health events, are the will of God, Muslim patients may be more likely to display acceptance of difficult circumstances and be agree with the instructions of health care providers (34).

This study has important implications for better understanding of meaning of self-care among diabetic patients in Southeast of Iran. The results suggest that cultural and religious components could affect diabetic patients' selfcare. Cultural characteristics of Iranian diabetic patients like negative aspect of family support decrease their sense of independence. Families may provide too much care, reducing the patient's independency. This finding reflects that sometimes cultural kinship relationship could be 
an obstacle in the process of achieving self-care among diabetic patents. Our results suggest that self-care behavior among diabetic patients could be improved by training family members to promote patients' independence, self-care ability and place the responsibility for self-care instead on diabetic patients themselves. Also, reducing dependence on family members empowers patients to gain confidence in their ability to manage symptoms.

This study showed the significant role of religious beliefs and optimistic or pessimistic thinking based on similar situations previously experienced by their own family members. Nurses would have recognized that the patients might hold optimistic or pessimistic views as well as religious beliefs about diabetes that differ from a nurse's. Nurses can use patients' religious belief to relieve their stress, and help them to retain a sense of control and maintain hope and sense of meaning and purpose in their life. They could also ask the patients a few, brief open-ended questions to learn the latters' religious beliefs and optimistic or pessimistic thinking. This information can then be used to negotiate with the patient as a nursing plan that improves patients' self-care.

The main limitation of this qualitative study is posed by the purposive selection of the sample. It is understood that the findings are limited to the study population and cannot be generalized based on the methodology (phenomenology) used. The goal of using phenomenology is to accurately describe the experience of the phenomenon under study for specific participants in one context (19).

\section{REFERENCES}

1. Wilkinson A, Whitehead L \& Ritchie L. Factors influencing the ability to self-manage diabetes for adults living with type 1 or 2 diabetes. International journal of nursing studies, 2014; 51(1): 111-122.

2. Rutty C J \& Soyao. G. Diabetes: Pioneer and Driver in Self Care Growth. . Self-Care Perspectives 2011, www.linkedin.com/pub/christopherrutty/22/909/260

3. Tol A, Baghbanian A, Mohebbi B, Shojaeizadeh D, Azam K, Shahmirzadi S E \& Asfia. A Empowerment assessment and influential factors among patients with type 2 diabetes. Journal of Diabetes \& Metabolic Disorders, 2013; 12(1):6

4. Collins M M, Bradley C P, O'sullivan T \& Perry I J. Self-care coping strategies in people with diabetes: a qualitative exploratory study. BMC endocrine disorders, 2009; 9(1): doi:10.1186/1472-6823-9-6

5. Sukkarieh, O A. The relationship among diabetes self-care, psychological adjustment, social support and glycemic control in the Lebanese population with type 2 diabetes mellitus. Nursing Dissertations, 2011. 2. http://hdl.handle.net/2047/d20002096

6. Association A D. Third-party reimbursement for diabetes care, self-management education, and supplies. Diabetes Care, 2003; 37(1):S118-S119.

7. Shrivastava $S$ R, Shrivastava $P \quad S \quad \&$ Ramasamy J. Role of self-care in management of diabetes mellitus. Journal of Diabetes \& Metabolic Disorders, 2013; 12(14):2-5.

8. Orem D Nursing: Concepts of practice. (4th ed.). St Louis, MO: Mosby. 1991.

9. Benzel-Lindley J A. Exploration of Factors Impacting the Self-Care of Elders with Diabetes. The University Of Arizona. 2005.

10. www.creating joy.com/taskforce/PDF/ACA_taskforce_selfca re.pdf

11. Thorne S, Paterson B \& C. R. themes described how self-care management was learned and experienced by patients with chronic illness. Qual Health Res, 2003; 13(13):37-52.

12. Hjelm K \& Bard K. Beliefs About Health and Illness in Latin-American Migrants with Diabetes Living in Sweden. Open Nursing Journal, 2013; 7:57-65.

13. Osman A \& Curzio J. South Asian cultural concepts in diabetes. Nursing times, 2012; 108(10):28- 30.

14. Burns N \& Grove S K Understanding nursing research. (3rd Ed), Philadelphia, PA : W. B. Saunders, 2003.

15. Streubert Speziale H J \& Carppenter D R. Qualitative research in nursing advancing the humanistic imperative, 3rd edition, Philadelphia, USA, Lippincott Williams\& Wilkins. 2003.

16. Lindseth A, Norberg A. A phenomenological hermeneutical method for researching lived 
experience. Scand J Car Sci, 2004; 18:145153.

17. Charalambous A. Hermeneutic phenomenological interpretations of patients with head and neck neoplasm experiences living with radiation-induced xerostomia: The price to pay? European Journal of Oncology Nursing, 2014; $18: 512-520$.

18. Morse J M \& Field P A. Qualitative research methods for health professionals ( $2^{\text {nd }}$ ed.). Thousand Oaks, CA: Sage 1995.

19. van Manen M. The tact of teaching. Albany: State University of New York, 1991.

20. Heidegger, M. Being and time. New York: Harper Perennial Modern Thought 1962.

21. Charalambous A, Papadopoulos IR, Beadsmoore A. Ricoeur's hermeneutic phenomenology: an implication for nursing research. Scand J Caring Sci, 2008; 22(4):637-42.

22. Funnell $M \quad M \quad \& \quad$ Anderson $R \quad M$ Empowerment and self-management of diabetes. Clinical diabetes, 2004; 22(3):123127.

23. Steed L, Cooke D \& Newman S. A systematic review of psychosocial outcomes following education, self-management and psychological interventions in diabetes mellitus. Patient education and counseling, 2003: 51(1):5-15.

24. De Silva D. Evidence: Helping people help themselves, The Health Foundation 2011.

25. Jones R A, Utz S W, Williams I C, Hinton I, Alexander G, Moore C, Blankenship J, Steeves R \& Oliver N. Family interactions among African Americans diagnosed with type 2 diabetes. The Diabetes Educator, 2008; 34(2):318-326.

26. Gallant M P, Spitze G D \& Prohaska T R. Help or hindrance? How family and friends influence chronic illness self-management among older adults. Research on Aging, 2007; 29(5):375-409.

27. Rosland A-M, Heisler M, Choi H-J, Silveira M J \& Piette J D. Family influences on selfmanagement among functionally independent adults with diabetes or heart failure: do family members hinder as much as they help? Chronic illness, 2010; 6(1):22-33.

28. Wang K-Y, Sung P-Y, Yang S-T, Chiang C-H \& Perng W-C. Influence of Family Caregiver Caring Behavior on COPD Patients' Self-Care Behavior in Taiwan. Respiratory care, 2012; 57(2):263-272.

29. Fournier M, Ridder D \& Bensing J. Optimism and adaptation to chronic disease: The role of optimism in relation to self-care options of type 1 diabetes mellitus, rheumatoid arthritis and multiple sclerosis. British Journal of Health Psychology, 2002; 7(4):409-432.

30. Rabiega J \& Cannon B J. The relationship of optimism with psychological and physical well-being. Journal of Psychology and the Behavioral Sciences, 2003:16-17.

31. Tirgari B, Iranmanesh S, Cheraghi M A \& Arefi A. Meaning of Spiritual Care: Iranian Nurses' Experiences. Holistic nursing practice, 2013; 27(4):199-206.

32. Iranmanesh S, Tirgari B \& Cheraghi M A. Developing and testing a spiritual care questionnaire in the Iranian context. Journal of religion and health, 2012; 51(4):1104-1116.

33. Johnstone M-J \& Kanitsaki O. Cultural safety and cultural competence in health care and nursing: An Australian study, RMIT University, 2005. 